\title{
Evaluating malaria case management at public health facilities in two provinces in Angola
}

Mateusz M. Plucinski ${ }^{1,2^{*}}$ D , Manzambi Ferreira ${ }^{3}$, Carolina Miguel Ferreira ${ }^{3}$, Jordan Burns ${ }^{4}$, Patrick Gaparayi ${ }^{5}$, Lubaki João ${ }^{5}$, Olinda da Costa ${ }^{5}$, Parambir Gill ${ }^{6}$, Claudete Samutondo ${ }^{7}$, Joltim Quivinja ${ }^{7}$, Eliane Mbounga ${ }^{8}$, Gabriel Ponce de León ${ }^{1,2}$, Eric S. Halsey ${ }^{1,2}$, Pedro Rafael Dimbu ${ }^{3}$ and Filomeno Fortes ${ }^{3}$

\begin{abstract}
Background: Malaria accounts for the largest portion of healthcare demand in Angola. A pillar of malaria control in Angola is the appropriate management of malaria illness, including testing of suspect cases with rapid diagnostic tests (RDTs) and treatment of confirmed cases with artemisinin-based combination therapy (ACT). Periodic systematic evaluations of malaria case management are recommended to measure health facility readiness and adherence to national case management guidelines.
\end{abstract}

Methods: Cross-sectional health facility surveys were performed in low-transmission Huambo and high-transmission Uíge Provinces in early 2016. In each province, 45 health facilities were randomly selected from among all public health facilities stratified by level of care. Survey teams performed inventories of malaria commodities and conducted exit interviews and re-examinations, including RDT testing, of a random selection of all patients completing outpatient consultations. Key health facility readiness and case management indicators were calculated adjusting for the cluster sampling design and utilization.

Results: Availability of RDTs or microscopy on the day of the survey was 71\% (54-83) in Huambo and 85\% (67-94) in Uíge. At least one unit dose pack of one formulation of an ACT (usually artemether-lumefantrine) was available in 83\% (66-92) of health facilities in Huambo and 79\% (61-90) of health facilities in Uíge. Testing rates of suspect malaria cases in Huambo were 30\% (23-38) versus 69\% (53-81) in Uíge. Overall, 28\% (13-49) of patients with uncomplicated malaria, as determined during the re-examination, were appropriately treated with an ACT with the correct dose in Huambo, compared to $60 \%$ (42-75) in Uíge. Incorrect case management of suspect malaria cases was associated with lack of healthcare worker training in Huambo and ACT stock-outs in Uíge.

Conclusions: The results reveal important differences between provinces. Despite similar availability of testing and $A C T$, testing and treatment rates were lower in Huambo compared to Uíge. A majority of true malaria cases seeking care in health facilities in Huambo were not appropriately treated with anti-malarials, highlighting the importance of continued training and supervision of healthcare workers in malaria case management, particularly in areas with decreased malaria transmission.

\footnotetext{
*Correspondence: mplucinski@cdc.gov

${ }^{1}$ Malaria Branch, Centers for Disease Control and Prevention, 1600 Clifton

Road, Atlanta, GA 30329, USA

Full list of author information is available at the end of the article
} 


\section{Background}

As in many sub-Saharan African countries, febrile illness is the single largest cause of healthcare seeking in Angola, responsible for $35 \%$ of outpatient visits and $20 \%$ of all inpatient services in public health facilities [1]. Much of the febrile illness can be attributed to malaria, as a substantial proportion of Angolans are infected with malarial parasites at any given time, measured to be $13.5 \%$ in children under five in 2015-2016 [2,3]. The entire country is endemic for malaria, although there is heterogeneity in malaria transmission, ranging from low, seasonal, epidemic-prone transmission in the dry south to high, year-round transmission in the wet, tropical north of the country. Despite having made substantial progress in rolling out malaria control interventions since the mid2000s, there has been an increase in malaria cases in Angola in 2015 and 2016 as seen in routine data collected by the Angola National Malaria Control Programme (NMCP), with a concurrent increase in malaria mortality. Thus, ensuring appropriate diagnosis and treatment for malaria is a critical health priority in Angola.

The strategy to reduce the malaria burden in Angola has two primary components: the reduction of malaria incidence through prevention activities, including vector control, and prompt diagnosis and appropriate treatment of acute malaria cases [1]. Angola has adopted World Health Organization (WHO) recommendations for malaria case management. Artemisinin-based combination therapy (ACT) was introduced as first-line treatment for uncomplicated malaria in 2006. In 2009, the country adopted a policy of universal laboratory confirmation for all suspect malaria cases either with microscopy, restricted primarily to hospitals and health centres, or rapid diagnostic tests (RDTs), used at all levels. The three ACT currently in use for first-line treatment in Angola are artemether-lumefantrine, artesunate-amodiaquine and dihydroartemisinin-piperaquine. Pregnant women in the first trimester are treated with oral quinine. Severe malaria cases are treated, in order of preference, with intravenous artesunate, intramuscular artemether or intravenous quinine.

Provision of appropriate care for an acute malaria case is a multi-step process that can be divided into four consecutive steps [4]: the ill person must seek care (access), be treated appropriately by a healthcare provider complying with national treatment guidelines (compliance), adhere to the prescribed treatment (adherence), and respond appropriately to the treatment (efficacy). The coverage at each step can be estimated separately from multiple sources, and the overall effective coverage can be calculated as the product of the coverage at each step. Community-based surveys can provide estimates for the access and adherence steps, and data from anti-malarial resistance monitoring provide estimates of anti-malarial efficacy.

Perhaps the most difficult step to assess is the compliance step, where appropriate case management of malaria cases is provided at health facilities. Its implementation is a complex undertaking that requires the confluence of several key activities. Firstly, health facilities must have all the necessary commodities to diagnose and treat malaria, including a sufficient and continuous supply of quality-assured malaria tests, reagents for microscopy when applicable, and appropriate antimalarials. Next, sufficient numbers of healthcare workers (HCWs) need to be trained in malaria case management, including use of RDTs, treatment, and when applicable, malaria microscopy. Next, HCWs need to be routinely supervised to ensure ongoing quality of service delivery and adherence to national treatment guidelines. Finally, accurate data on suspected and confirmed cases of malaria must be recorded and reported onward to ensure that decisions about malaria prevention and treatment can be targeted where they will have the greatest impact.

Assessment of the compliance step cannot be done from community-based surveys and necessitates collection of individual data at the health-facility level to characterize $\mathrm{HCW}$ performance for each of the steps in the case-management pathway. Evaluations in the form of systematic health facility surveys are a useful tool for monitoring the functioning of the different components of malaria case management implementation, especially in the context of changing malaria incidence and policies [5-7]. The Angola NMCP and the US President's Malaria Initiative (PMI) conducted a malaria-specific health facility survey in the central province of Huambo in 2007, coinciding with the start of PMI support in the country. Serving as a baseline, the survey found overall poor practices by HCWs with substantial weaknesses in testing and treatment practices [8].

In early 2016, the Angola NMCP implemented a subsequent, malaria-focused health facility survey in Huambo Province, the site of the 2007 survey, and in Uíge Province, a PMI-supported province in the north of the country. The objective was to assess health facility readiness for malaria diagnosis and treatment and to evaluate the quality of malaria case management.

\section{Methods}

A cross-sectional survey of health facilities was independently carried out in two provinces (Fig. 1): Huambo Province with meso-endemic-stable malaria transmission in the central highlands of Angola and Uíge Province with hyperendemic malaria transmission in northern Angola, an area covered with grassland savannahs interspersed with dense tropical forest. The survey took place 

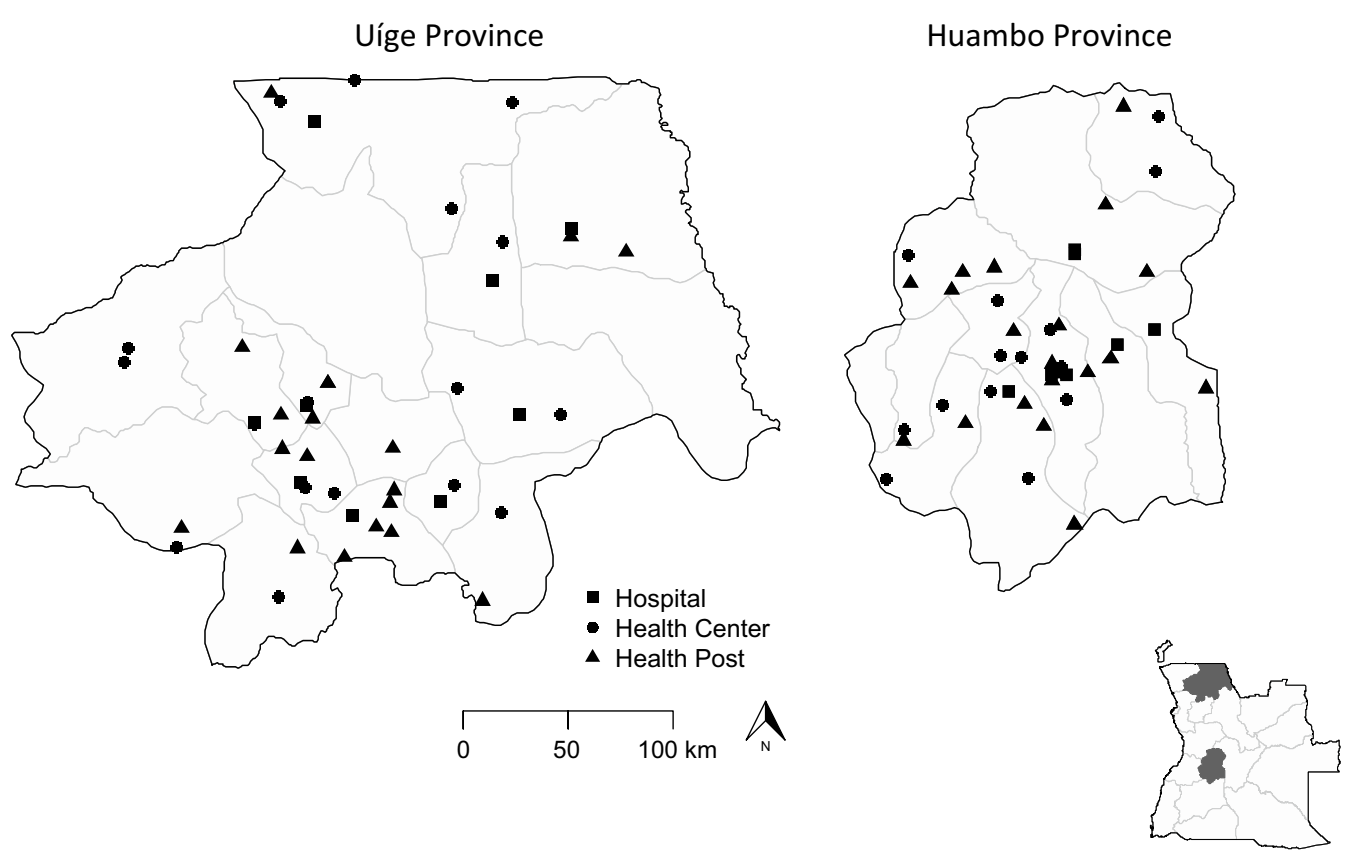

Fig. 1 Location of health facilities visited during health facility surveys in Angola, 2016

in February 2016, at the peak of malaria transmission season in both provinces.

In each province, an exhaustive list of all public health facilities was obtained from the Provincial Directorate of Health, encompassing 230 health facilities in Huambo and 321 in Uíge. A total of 45 health facilities were randomly selected in each province, stratifying by health facility classification: nine hospitals, 18 health centres and 18 health posts. In each health facility, a maximum of five HCWs present during the visit were purposively chosen for interviews based on malaria case management workload. Additionally, a maximum of 20 patients were randomly invited to be interviewed and undergo a re-examination by a study clinician. All patients attending the outpatient department on the day of the visit were eligible for inclusion in the survey, independent of demographics or symptoms. The number of outpatient visits 1 week prior to the visit was abstracted from the health facility register, a sampling interval was determined, and randomly selected patients were invited to participate as they arrived. If the health facility saw fewer than 20 patients, all patients were invited to take part. In health facilities with separate paediatric and adult outpatient clinics, ten patients were chosen from each clinic.

The survey was powered to obtain a point estimate of the proportion of patients with an acute malaria episode treated with a first-line anti-malarial with a 95\% confidence interval precision of $10 \%$. Estimating that $40 \%$ of all patients would be suspect malaria cases, and assuming a $44 \%$ test positivity rate estimated from routine health facility data, a $75 \%$ treatment rate and a design effect of 2 , the target sample size was calculated to be 820 patients per province.

\section{Data collection}

In each province, four survey teams, each composed of a national-level supervisor and three interviewers, visited selected health facilities. The teams spent a full workday in each health facility, with data collection lasting 3 weeks per province. Survey teams carried out three primary activities: interviews with HCWs and facility directors; exit interviews and re-examinations of patients; and an inventory of 16 malaria commodities. Interviews were conducted using standardized questionnaires. During interviews with $\mathrm{HCWs}$, interviewers enquired about $\mathrm{HCW}$ training, supervision and access to guidelines and job-aids.

Selected patients agreeing to participate in the survey were given a study identification card upon arrival at the health facility and were asked to present to the survey team once they completed their consultation and prior to leaving the health facility. During the exit interviews, interviewers asked about the history and symptoms of the current illness and asked patients to recall whether they were asked about fever by the HCW, whether they were tested for malaria during the consultation, what treatments they were prescribed, and what counselling they were provided by the HCW. Data on testing 
and treatment were verified through examination of any available patient cards and prescriptions and any drugs that were dispensed at the health facility. For the reexamination, survey teams took patient temperatures, performed an RDT (SD Bioline P. falciparum/P. vivax, Yongin, Republic of Korea), and provided artemetherlumefantrine, supplied by the Angolan NMCP, dosed according to weight, for RDT-positive patients that had not been prescribed appropriate anti-malarial treatment at the health facility.

At the end of the health facility visit, survey teams abstracted data from the health facility register for the selected patients and recorded the total number of outpatient visits during the day of the visit. All data collection was done on electronic tablets using SurveyCTO software (Dobility, Cambridge, USA).

\section{Variable definitions}

Key health facility readiness indicators [9], including availability of key malaria commodities and HCW training and supervision, were calculated separately for each province. For each of the 16 malaria commodities, the proportion of health facilities managing each commodity (defined as regularly receiving and using the commodity) and the proportion stocked out on the day of visit (excluding expired commodities), were calculated. Any $\mathrm{HCW}$ that reported attending any malaria case management training was counted as having been trained in malaria case management.

Standard indicators for malaria case management [9], including the testing rate of suspect cases and treatment rate of confirmed cases, were calculated separately for each province. A suspect malaria case was defined as a patient complaining of fever or history of fever in the last $24 \mathrm{~h}$, as recorded during the exit interview, or a with a temperature above $37.5^{\circ} \mathrm{C}$ measured during the re-examination. A true case was defined as a suspect malaria case testing RDT-positive during the exit interview. Confirmed cases were defined as laboratory-confirmed cases based on testing by health facility staff that also tested RDT-positive during the exit interview. Correct management of a suspect malaria case was defined as testing by either RDT or microscopy at the health facility, and treatment with or prescription of a first-line anti-malarial with the correct dose only among patients testing positive during the re-examination (true positives). Patients with symptoms of severe malaria or general danger signs were excluded from the analysis.

The four key steps in the case-management pathway were evaluated separately to determine HCW performance: the proportion of patients who were asked about fever, spontaneously complained of fever, or had their temperature taken; the proportion tested by RDT or microscopy; the proportion treated or prescribed a firstline anti-malarial; and, the proportion receiving or prescribed the correct dose. To identify potential gaps in the case-management pathway for true malaria cases, the proportion of patients correctly managed at each step in the pathway was calculated, as was the cumulative proportion of patients correctly managed up to, and including, each step in the pathway.

For patients prescribed or given an ACT by the HCW, the quality of counselling provided by the $\mathrm{HCW}$ was assessed. Patients were asked to recall what instructions were given by the HCW regarding how to administer the $\mathrm{ACT}$ and under what circumstances they should return to the health facility. Patients were also asked to recite the dosing schedule for the prescribed ACT, including the number of tablets per dose, the number of doses per day, and the total number of days of therapy.

\section{Analysis}

Health facility-level indicators were estimated adjusting by weighting by the inverse of the probability of health facility selection, and patient-level indicators were estimated adjusting by weighting by the inverse of the product of the probability of health facility selection and the probability of patient selection to adjust for utilization, using the R survey package [10].

Logistic regression was used to explore the relationship between a suspect malaria case being correctly managed and health facility type, availability of ACT and RDTs or microscopy, proportion of HCWs in the health facility trained in malaria case management, and the proportion of HCWs supervised in the last 6 months. Gender and age of the patient and the proportion of patients at the health facility testing positive for malaria during the re-examination (a measure of local malaria endemicity) were included as potential confounders.

Spatial heatmaps generated with Gaussian kernel smoothing were created for each province for six indicators: the proportion of patients with malaria, as determined during the re-examination; the proportion of suspect malaria cases correctly managed; the proportion of HCWs supervised in the last 6 months; the proportion of HCWs trained in malaria case management; the proportion of health facilities with ACT available; and the proportion of health facilities with RDTs or microscopy available.

All statistical analysis was done in $\mathrm{R}$ version 3.3.0 ( $\mathrm{R}$ Foundation for Statistical Computing, Vienna, Austria).

\section{Ethical considerations}

The survey was classified as a non-research, programme evaluation activity by Human Subjects Review Boards at the US Centers for Disease Control and Prevention and 
the Angolan Ministry of Health. All interviewed patients provided written informed consent.

\section{Results}

Teams visited 89 out of 90 chosen health facilities, as one selected health facility in Huambo no longer existed, representing an error in the list provided. The final breakdown by health facility type (Table 1 ) did not match the sampling strategy since several health facilities in each province were misclassified on the lists provided by the provinces.

Availability of malaria tests and treatments on the day of the visit was similar in both provinces, with $71 \%$ (95\% CI 54-83) of health facilities in Huambo and $85 \%$ (67-94) in Uíge with access to RDTs or microscopy, and $83 \%(66-92)$ of health facilities in Huambo and $79 \%$ (61-90) in Uíge with access to at least one formulation of an unexpired ACT in at least one unit dose package format (Table 2). However, stock-out rates of age-specific formulations were high in both provinces, ranging from 29 to $81 \%$ for artemether-lumefantrine, and 25 to $100 \%$, skewed towards $100 \%$, for artesunate-amodiaquine and dihydroartemisinin-piperaquine, which were only managed in a small subset of health facilities (see Additional file 1: Table S1). Availability of malaria commodities other than ACT and RDTs, such as severe malaria treatment, was also generally low in both provinces, with stock-out rates ranging from 25 to $100 \%$ (see Additional File 1: Table S1).

A total of $119 \mathrm{HCWs}$ were interviewed in Huambo and 93 in Uíge. Over $90 \%$ of health facilities in both provinces reported having at least one $\mathrm{HCW}$ trained in malaria case

Table 1 Numbers and characteristics of health facilities, healthcare workers, and patients surveyed in Huambo and Uige Provinces, Angola, 2016

\begin{tabular}{|c|c|c|c|}
\hline & \multicolumn{3}{|l|}{ n (\%) } \\
\hline & Huambo & Uíge & Total \\
\hline Health facility & 44 & 45 & 89 \\
\hline Hospital & $8(19)$ & $9(20)$ & $17(19)$ \\
\hline Health centre & $15(35)$ & $17(38)$ & $32(36)$ \\
\hline Health post & $20(47)$ & $19(42)$ & $39(44)$ \\
\hline Healthcare workers interviewed & 119 & 93 & 212 \\
\hline Patients interviewed & 590 & 634 & 1224 \\
\hline$<5$ Years & $222(38)$ & $162(26)$ & $384(31)$ \\
\hline $5-15$ Years & $84(14)$ & $141(22)$ & $225(18)$ \\
\hline$>15$ Years & $284(48)$ & $331(52)$ & $615(50)$ \\
\hline Female & $367(62)$ & $396(62)$ & $763(62)$ \\
\hline Suspect malaria cases & $360(61)$ & $430(68)$ & $790(65)$ \\
\hline True malaria cases ${ }^{\mathrm{a}}$ & $51(9)$ & $242(38)$ & $293(24)$ \\
\hline
\end{tabular}

a Defined as RDT-positive during survey re-examination
Table 2 Standard key indicators on health facility readiness for malaria care delivery, as assessed in health facility surveys in Huambo and Uíge Provinces, Angola, 2016

\begin{tabular}{|c|c|c|c|c|}
\hline & \multicolumn{2}{|c|}{ Huambo } & \multicolumn{2}{|c|}{ Uíge } \\
\hline & $\%$ & $95 \% \mathrm{Cl}$ & $\%$ & $95 \% \mathrm{Cl}$ \\
\hline \multicolumn{5}{|l|}{ Health facilities } \\
\hline Offering any malaria diagnostic services & 94 & 79-99 & 100 & a \\
\hline RDT & 94 & 79-99 & 100 & a \\
\hline Malaria microscopy & 21 & $12-33$ & 4.5 & $2-9$ \\
\hline Offering any malaria treatment & 100 & a & 100 & a \\
\hline $\begin{array}{l}\text { With RDT or malaria microscopy available } \\
\text { on day of visit }\end{array}$ & 71 & $54-83$ & 85 & $67-94$ \\
\hline $\begin{array}{l}\text { With any formulation of ACT available on } \\
\text { day of visit }\end{array}$ & 83 & $66-92$ & 79 & $61-90$ \\
\hline $\begin{array}{l}\text { With at least one HCW trained on RDT } \\
\text { use }\end{array}$ & 95 & $78-99$ & 90 & $73-97$ \\
\hline $\begin{array}{l}\text { With at least one HCW trained on malaria } \\
\text { microscopy }\end{array}$ & 24 & $15-36$ & 4.5 & $2-9$ \\
\hline $\begin{array}{l}\text { With at least one HCW trained on malaria } \\
\text { treatment }\end{array}$ & 99 & $96-100$ & 98 & $93-99$ \\
\hline $\begin{array}{l}\text { With guidelines for diagnosis and treat- } \\
\text { ment of malaria }\end{array}$ & 96 & $90-98$ & 51 & $34-68$ \\
\hline $\begin{array}{l}\text { HCWs trained in malaria case manage- } \\
\text { ment }\end{array}$ & 81 & $73-87$ & 80 & $69-89$ \\
\hline HCWs supervised in last 6 months & 58 & $49-68$ & 69 & $52-83$ \\
\hline
\end{tabular}

$R D T$ rapid diagnostic test, $A C T$ artemisinin-based combination therapy, $H C W$ healthcare worker

a Confidence intervals undefined

management and RDT use; $81 \%$ (73-87) of HCWs interviewed in Huambo and $80 \%$ (69-89) in Uíge reported receiving malaria case management training. In Huambo, $58 \%$ (49-68) of HCWs interviewed reported receiving a supervisory visit in the last 6 months, compared to $69 \%$ (52-83) in Uíge. Only $24 \%(15-36)$ of health facilities in Huambo and 4\% (2-9) in Uíge reported having a trained microscopist (Table 2).

In Huambo, 590 patients were interviewed, with 360 (61\%) meeting the criteria of a suspect malaria case (Table 1). In Uíge, 430 of 634 (68\%) interviewed patients were suspect malaria cases. In Huambo, $14 \%$ (9-23) of suspect malaria cases were true malaria cases (tested positive by RDT during the re-examination), compared to $53 \%$ (45-60) in Uíge.

Among suspect malaria cases, only 30\% (23-38) were tested by RDT or microscopy in Huambo, compared to $69 \%$ (53-81) in Uíge (Table 3). An additional 9\% (6-14) of patients not meeting the suspect malaria case definition were tested in Huambo, increasing to $56 \%(39-72)$ in Uíge. In both provinces, testing with RDTs was substantially more common than microscopy. Patients undergoing testing at the health facility who were confirmed to have a positive RDT during the 
re-examination were likely to have been treated with a first-line anti-malarial, with treatment rates of $74 \%$ (52-88) in Huambo and 86\% (74-93) in Uíge. A minority ( $2 \%$ in each province) of patients that had been tested at the health facility and were negative by RDT during the reexamination received anti-malarial treatment at the health facility. Overall, 27\% (21-35) of suspect malaria cases were tested and were treated according to the test result in Huambo, compared to 59\% (43-74) in Uíge. Among suspect malaria cases testing positive during the re-examination (true malaria cases), only $28 \%(13-49)$ had been given or prescribed a first-line anti-malarial with the correct dose in Huambo, compared to 60\% (4275) in Uíge.

Analysis of the case-management pathway in these true malaria cases reveals that in Huambo the step least likely to happen was diagnostic testing. This step accounted for an overwhelming contribution to incorrect case management, with $57 \%$ of patients falling out of the correct case-management pathway at the testing step (Fig. 2). In contrast, in Uíge, performance along the entire pathway was more uniform, with each step being performed at a rate ranging from 76 to $96 \%$.

In Huambo, the proportion of HCWs at the health facility reporting having received training in malaria case management was the only factor significantly associated with correct management of suspect malaria cases (adjusted OR: 2.7, 95\% CI 1-8) (Table 4). Notably, correct malaria case management was not significantly associated with ACT or RDT availability. In contrast, in Uíge, availability of ACT was the strongest predictor of correct management of suspect malaria cases (adjusted OR: 7.2, 95\% CI 3-20). HCWs were also more likely to manage suspect malaria cases incorrectly in older age categories in Uíge. In both provinces the majority of incorrect management of suspect cases of malaria (61\% in Huambo and $73 \%$ in Uíge) took place in health facilities where both malaria testing and ACT were available.

A high proportion (above 85\%) of patients prescribed an ACT in either province were instructed by the $\mathrm{HCW}$ on how to take the $\mathrm{ACT}$ and were able to correctly recite the dosing schedule (Table 5). However, the first dose of ACT was given at the health facility only $4 \%(95 \%$ CI 1-15) of the time in Huambo versus $45 \%$ (22-70) in Uíge. The $\mathrm{HCW}$ explained how to take artemetherlumefantrine, the most commonly prescribed ACT, with food only $34 \%(15-59)$ of the time in Huambo and $19 \%$ (11-31) of the time in Uíge. Less than half of all patients prescribed an ACT in both provinces reported being instructed to return to the health facility if the symptoms worsened or did not improve.

There was substantial spatial heterogeneity in the proportion of patients presenting with malaria in both provinces, indicative of underlying spatial variation in malaria transmission (see Additional File 1: Figure S1, S2). There was also substantial heterogeneity in the performance on malaria indicators. In Uíge, the northeast of the province exhibiting very high malaria positivity also had the highest rates of ACT and RDT stock-outs, and the lowest rates of supervision and training.

Table 3 Standard key indicators on healthcare worker performance in malaria case management, as assessed in health facility surveys in Huambo and Uíge Provinces, Angola, 2016

\begin{tabular}{|c|c|c|c|c|}
\hline & \multicolumn{2}{|c|}{ Huambo } & \multicolumn{2}{|c|}{ Uíge } \\
\hline & $\%$ & $95 \% \mathrm{Cl}$ & $\%$ & $95 \% \mathrm{Cl}$ \\
\hline Suspect malaria cases receiving malaria test & 30 & $23-38$ & 69 & $53-81$ \\
\hline$<5$ Years & 30 & $23-38$ & 82 & $65-92$ \\
\hline RDT & 25 & $18-33$ & 81 & $64-91$ \\
\hline Microscopy & 5 & $2-13$ & 1 & $0.2-4$ \\
\hline$\geq 5$ Years & 30 & $21-41$ & 64 & $46-78$ \\
\hline RDT & 28 & $19-39$ & 63 & $46-78$ \\
\hline Microscopy & 3 & $1-10$ & 1 & $0.2-2$ \\
\hline Confirmed malaria cases treated with appropriate anti-malarial & 74 & $52-88$ & 86 & 74-93 \\
\hline Suspect malaria cases negative for malaria ${ }^{a}$ but treated with anti-malarial & 2 & $0.4-5.6$ & 2 & $0.7-6.8$ \\
\hline Suspect malaria cases not tested and treated with appropriate anti-malarial & 1 & $0.3-4$ & 7 & $2-23$ \\
\hline Suspect malaria cases managed correctly ${ }^{\mathrm{b}}$ & 27 & $21-35$ & 59 & $43-74$ \\
\hline True malaria cases appropriately treated ${ }^{c}$ & 28 & $13-49$ & 60 & $42-75$ \\
\hline
\end{tabular}

$R D T$ rapid diagnostic test

a During re-examination

b Tested and treated with first-line anti-malarial with correct dose only if positive

c Treated with first-line anti-malarial with correct dose 


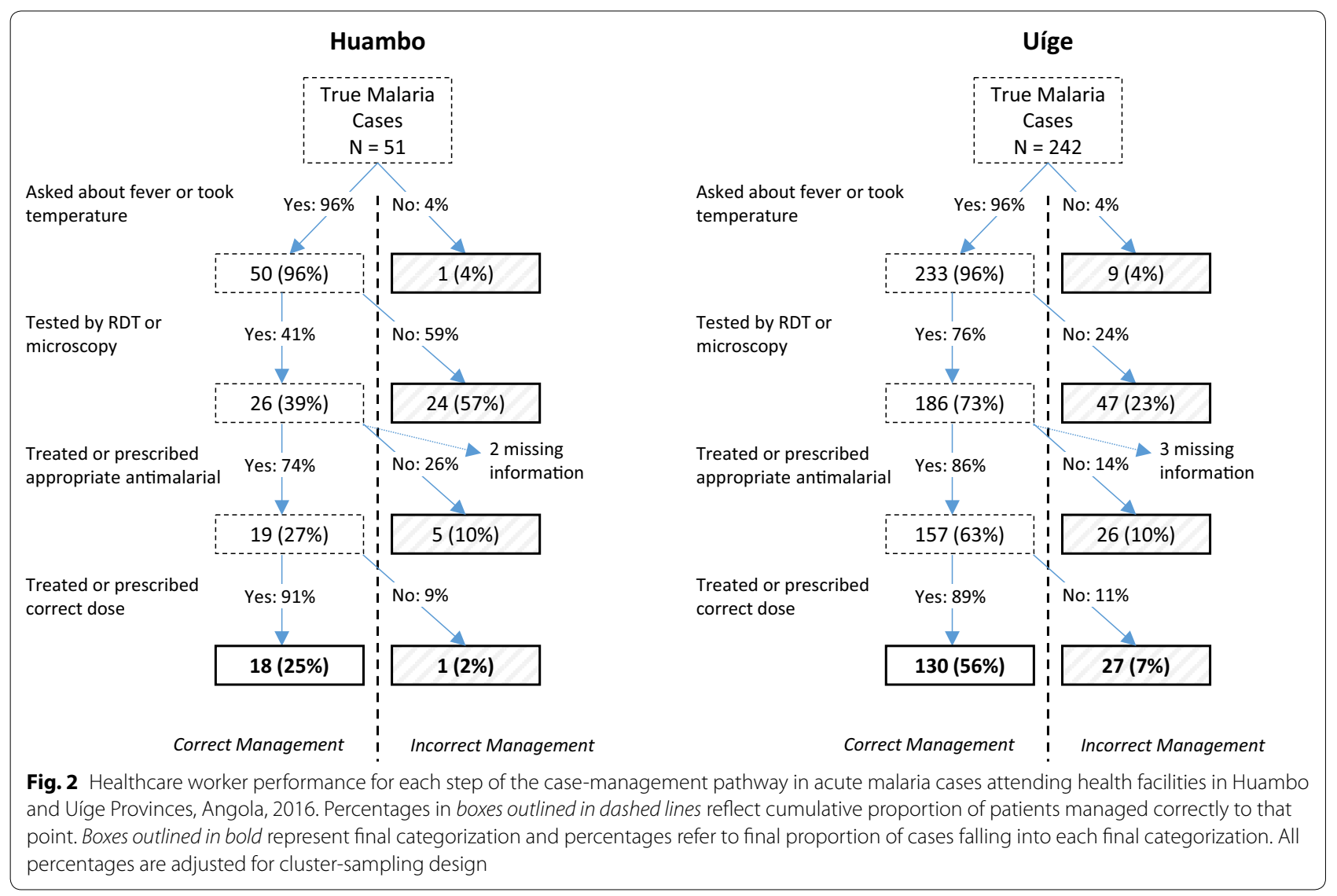

Table 4 Factors associated with correct management of suspect malaria cases attending health facilities in Huambo and Uíge Provinces, Angola, 2016

\begin{tabular}{|c|c|c|c|c|}
\hline \multirow[t]{2}{*}{ Variable } & \multicolumn{2}{|l|}{ Huambo } & \multicolumn{2}{|l|}{ Uíge } \\
\hline & Adjusted odds ratio & $95 \% \mathrm{Cl}$ & Adjusted odds ratio & $95 \% \mathrm{Cl}$ \\
\hline \multicolumn{5}{|l|}{ Patient age } \\
\hline$<5$ Years & Ref & - & Ref & - \\
\hline $5-15$ Years & 0.86 & $0.4-2$ & 0.68 & $0.4-1$ \\
\hline$>15$ Years & 1.3 & $0.7-2$ & 0.4 & $0.2-0.7$ \\
\hline \multicolumn{5}{|l|}{ Patient sex } \\
\hline Female & Ref & - & Ref & - \\
\hline Male & 0.89 & $0.5-1$ & 0.66 & $0.4-1$ \\
\hline \multicolumn{5}{|l|}{ Health facility type } \\
\hline Hospital & Ref & - & Ref & - \\
\hline Health centre & 1.2 & $0.6-2$ & 1.6 & $0.9-3$ \\
\hline Health post & 0.71 & $0.4-1$ & 1.0 & $0.6-2$ \\
\hline RDT or microscopy available on day of visit & 1.7 & $0.7-5$ & 2.5 & $1-7$ \\
\hline ACT available on day of visit & 0.55 & $0.3-1$ & 7.2 & $3-20$ \\
\hline Proportion of interviewed HCWs supervised in last 6 months & 0.69 & $0.3-1$ & 1.2 & $0.6-2$ \\
\hline Proportion of interviewed HCWs trained in malaria case management & 2.7 & $1-8$ & 1.4 & $0.6-4$ \\
\hline Proportion of patients testing true positive by RDT during re-examination & 1.9 & $0.3-10$ & 0.67 & $0.2-2$ \\
\hline
\end{tabular}

$R D T$ rapid diagnostic test, $A C T$ artemisinin-based combination therapy, $H C W$ healthcare worker 
Table 5 Quality of counselling in patients prescribed an ACT as assessed during exit interviews in health facility surveys in Huambo and Uíge Provinces, Angola, 2016

\begin{tabular}{|c|c|c|c|c|}
\hline & \multicolumn{2}{|c|}{ Huambo } & \multicolumn{2}{|c|}{ Uíge } \\
\hline & $\%$ & $95 \% \mathrm{Cl}$ & $\%$ & $95 \% \mathrm{Cl}$ \\
\hline Given first dose at health facility & 4 & $0.8-15$ & 45 & $22-70$ \\
\hline Given instructions on how to take $A C T$ & 85 & $57-96$ & 89 & $76-96$ \\
\hline Able to correctly recite dosing schedule ${ }^{a}$ & 90 & $78-96$ & 85 & $77-91$ \\
\hline \multicolumn{5}{|l|}{ Received instructions to } \\
\hline \multicolumn{5}{|l|}{ Take with food } \\
\hline $\mathrm{AL}$ & 34 & $15-59$ & 19 & $11-31$ \\
\hline DP & 29 & $12-56$ & 98 & $88-100$ \\
\hline \multicolumn{5}{|l|}{ Take on empty stomach } \\
\hline$A L$ & 3 & $0.6-13$ & 7 & $4-14$ \\
\hline DP & 29 & $12-56$ & 0 & - \\
\hline Complete all doses & 72 & $51-86$ & 58 & $41-74$ \\
\hline Return if worse & 44 & $25-64$ & 26 & $15-40$ \\
\hline Return if no improvement & 38 & $21-58$ & 31 & $20-44$ \\
\hline
\end{tabular}

$A C T$ artemisinin-based combination therapy, $A L$ artemether-lumefantrine, $D P$ dihydroartemisinin-piperaquine

a Correct number of tablets per dose, doses per day, and total duration of treatment. Calculated only for subset of patients prescribed the correct dose

\section{Discussion}

The assessment revealed stark differences in the state of malaria case management in the two provinces. Over two-thirds of patients presenting with acute malaria infection in Huambo left the health facility without having been given or prescribed an appropriate anti-malarial. The poor performance of Huambo HCWs manifested in very low testing rates, with $30 \%$ of all febrile patients undergoing a laboratory diagnostic test for malaria, showing no improvement over the $31 \%$ testing rate measured in 2007 [8], despite the introduction and expansion of RDTs in the intervening time.

Despite an immense increase in RDT and ACT availability in sub-Saharan Africa in recent years, the overall proportion of malaria cases appropriately treated with anti-malarials is still low across the continent [11]. Although access to healthcare is an important factor, errors in malaria case management continue to be a major factor in the low population coverage. Commonly, the testing step in the case-management pathway is the main determinant of overall quality [12-15], and the results of this survey are no exception. The change to a policy of universal confirmation of suspected cases of malaria, made possible by the large-scale introduction of RDTs, has had a complex and variable effect on prescribing practices. In some settings, anti-malarial prescriptions have increased while in others it has decreased following the expansion of malaria testing [16]. In Huambo, for which two time points are available, $43 \%$ of true malaria cases that were not tested were still diagnosed with malaria (clinical diagnosis) in 2007. However, in 2016, empiric treatment with antimalarials of suspect cases that were not tested was only $1 \%$. Treatment of test-negative patients decreased from $60 \%$ in 2007 to $2 \%$ in 2016 . However, because testing rates were measured to only be $30 \%$ in 2016 , most true malaria cases were not treated with an ACT in Huambo, compared to a $49 \%$ rate of correct treatment of true malaria cases in 2007. This overall decrease in correct treatment of true malaria cases is a cautionary sign that the withdrawal of empiric treatment of malaria must be accompanied by a sustained effort to attain high testing rates [17].

In contrast to Huambo, malaria case management in Uíge was found to be relatively well functioning, with $\mathrm{HCW}$ performance at each step in the testing and treatment pathway above $75 \%$. However, even with high performance at each individual step, overall effective coverage was low. Ultimately, only $56 \%$ of all malaria cases were correctly managed at all steps, an example of how overall low effective coverage can arise despite high coverage at individual steps in the context of interventions that require multiple sequential steps to be performed correctly [18]. Because there is currently no redundancy built into the system, for example in the form of empiric treatment, effective coverage will always be driven by the weakest steps in the case-management pathway.

The divergence of the two provinces should be interpreted in the context of historical malaria epidemiology in the two areas. Despite being in the highlands with moderate rainfall, Huambo routinely reported among the highest rates of malaria in any Angolan province in the last decade. As recently as 2010, Huambo reported over 500,000 annual cases of malaria [19]. However, by 2013, case numbers had fallen to just over 40,000 annual cases, $12 \%$ of the 2010 total, following intense vector control interventions and the scale-up of modern malaria control. This was reflected in the fact that only 51 malaria cases were identified out of 590 interviewed patients. This dramatic reduction in malaria cases might have caused a sense of complacency in HCWs in Huambo, removing suspicion of malaria and explaining the low observed testing rate. However, there are still pockets in Huambo with substantial numbers of malaria cases, particularly in the northeast corner of the province.

Appropriateness of case management of suspect malaria cases in Huambo was found to be associated with the proportion of HCWs trained in malaria case management at the health facility, which suggests that an effort to increase the total number of HCWs trained in malaria case management should improve this particular indicator. However, given the already high percentage of $\mathrm{HCWs}$ reporting being trained in malaria case management $(81 \%)$, there is little room for this strategy to increase the 
rate of correct management. Improving ACT and RDT availability will also not completely address the root of the problem, as evidenced by the finding that most incorrect management of cases occurred in health facilities that had ACT and testing facilities available. Only an intervention that can change the mindset of HCWs to enforce the need to rule out malaria in all patients presenting with fever would be expected to substantially improve the overall outcome, since the decision to use available test kits was the weakest step in the process.

Uíge, in contrast to Huambo, has been reporting a relatively steady number of malaria cases to the NMCP over the last 5 years, approximately 150,000-250,000 cases per year, with no clear year-to-year trend. A different climate and economic situation have made malaria transmission in Uíge more recalcitrant than in Huambo, evidenced by the much larger proportion of malaria infections among interviewed patients. The survey suggests that HCWs in Uíge are largely cognizant of the role of malaria in the ill population they serve, with testing rates of suspect cases reaching $77 \%$. Nevertheless, the weakest step in the casemanagement pathway was the diagnostic testing step. Since inappropriate case management was found to be associated with ACT stock-outs, improving the availability of malaria commodities should likely improve malaria care delivery. Nevertheless, this might prove challenging due to the inaccessibility of certain areas in the province. Certain health facilities were only reached after 16-h drives, with flooded, muddy and sandy roads hampering access. Notably, health facilities in the difficult-to-reach northeast of the province where the proportion of malaria cases was the highest were also the ones least likely to have ACT or RDTs on hand, or be staffed by HCWs trained in malaria case management or routinely supervised. Extra effort is needed to focus on areas with this profile to provide quality malaria care where it is most needed.

In both provinces, $\mathrm{HCWs}$ were generally effective in explaining the ACT dosing schedule to patients. However, only a minority of patients were instructed to take artemether-lumefantrine with food (34\% in Huambo and $19 \%$ in Uíge). Artemether-lumefantrine should be administered with fatty foods to aid in absorption, and inappropriate administration of artemether-lumefantrine might lead to lower blood drug levels and increase the risk of treatment failure [20]. The importance of counselling patients to take artemether-lumefantrine with fatty foods should be emphasized in HCW training.

This survey was limited to some extent by a lower than expected sample size, having achieved only $75 \%$ of its target sample size. This was driven primarily by low patient flow in certain health facilities, particularly lower-level health facilities. As a result the overall average number of patients enrolled per health facility was 14 versus the expected 20. While the design effect for the indicator driving the sample size calculation, the proportion of patients with an acute malaria episode treated with a first-line anti-malarial, was 1.7 in Huambo, it was 10 in Uíge, substantially higher than the expected value of 2 , and a major contributor to the large confidence intervals around the case management indicators in Uíge. Moreover, in Huambo, the low test positivity rate resulted in only 51 true malaria cases, reducing the precision of the survey's estimates of certain case management indicators. Another limitation to the study was the choice of an exit interview strategy, which while accurate for indicators related to procedures such as RDT testing, can be less accurate for indicators related to counselling [21, 22].

This health facility survey was carried out during a difficult moment for malaria control in Angola. The fall in the price of oil and subsequent financial crisis coinciding with the loss of donor support from The Global Fund to Fight AIDS, Tuberculosis and Malaria (Global Fund) resulted in a weakening of malaria control efforts throughout Angola, starting in 2014 and continuing into 2016. Recent years have seen routine stock-outs of ACT and RDTs throughout Angola. This survey was performed shortly after an emergency shipment of malaria commodities from the Global Fund, and the ACT and RDT levels reported are likely not representative of their availability throughout the year. Yet, even during this survey, the stock-out rates of individual formulations of ACT were high, making treatment of different age categories even more difficult for HCWs.

In contrast to other sub-Saharan African countries reporting increases in malaria cases in recent years, Angola's increase in morbidity has been accompanied by an increase in malaria mortality [19], likely aggravated by a yellow fever epidemic. Although this survey was not designed to examine clinical management of severe malaria cases, delayed or inappropriate management of uncomplicated malaria cases increases the likelihood of progression to severe disease and higher risk for malaria mortality. Moreover, the low availability of intravenous artesunate and intramuscular artemether means that most severe malaria cases are unlikely to be treated with the first-line therapies in Angola.

\section{Conclusion}

Improvement of malaria case management is crucial to mitigate the effects of the current increase in malaria transmission in Angola. The results from this survey confirm modelling estimates that the vast majority of acute malaria episodes in Angola are not treated with appropriate anti-malarial therapy [11]. A main factor is low access to the formal healthcare sector, estimated to be $45 \%$ nationwide [1]; this could be mitigated by increasing 
the numbers of functional health centres or by establishing a programme for integrated community case management of childhood illness. However, the results reported here show that poor malaria case management at health facilities also contributes to the overall low coverage. The availability of malaria commodities and rates of appropriate treatment of the minority of malaria cases that do seek care in health facilities must be improved to decrease malaria morbidity and mortality in Angola.

\section{Additional file}

Additional file 1: Table S1. Availability of malaria commodities during visits to health facilities in Huambo and Uíge Provinces, Angola, 2016. Figure S1. Geographic distribution of malaria case management and readiness indicators, Huambo Province, Angola, 2016; HF: health facility, RDT: rapid diagnostic test, ACT: artemisinin-based combination therapy. Figure S2. Geographic distribution of malaria case management and readiness indicators, Uíge Province, Angola, 2016; HF: health facility, RDT: rapid diagnostic test, ACT: artemisinin-based combination therapy.

\section{Authors' contributions}

MMP, PRD, PGa, EM, GPdL, and FF planned and designed the study. MMP, MF CMF, JB, LJ, OdC, PGi, CS, JQ, and GPdL supervised the study teams collecting the data. MMP, PRD, ESH, PGa, and FF prepared the manuscript. All authors read and approved the final manuscript.

\section{Author details \\ ${ }^{1}$ Malaria Branch, Centers for Disease Control and Prevention, 1600 Clifton Road, Atlanta, GA 30329, USA. ${ }^{2}$ President's Malaria Initiative, Centers for Dis- ease Control and Prevention, Atlanta, GA, USA. ${ }^{3}$ National Malaria Control Program, Ministry of Health, Luanda, Angola. ${ }^{4}$ President's Malaria Initiative, USAID, Washington, DC, USA. ${ }^{5}$ Management Sciences for Health, Luanda, Angola. ${ }^{6}$ Management Sciences for Health, Washington, DC, USA. ${ }^{7}$ Field Epidemiology and Laboratory Training Program, Ministry of Health, Luanda, Angola. ${ }^{8}$ President's Malaria Initiative, USAID, Luanda, Angola.}

\section{Acknowledgements}

Investigators thank all survey staff, two MEASURE Evaluation consultants, and the healthcare workers and patients who agreed to be interviewed, and are grateful for the generous support of the Provincial Directorates of Health of Huambo and Uíge.

\section{Competing interests}

The authors declare that they have no competing interests.

\section{Ethics approval and consent to participate}

The survey was classified as a non-research, program evaluation activity by Human Subjects Review Boards at the US Centers for Disease Control and Prevention and the Angolan Ministry of Health. All interviewed patients provided written informed consent.

\section{Funding}

The study was funded by the US President's Malaria Initiative. The findings and conclusions in this report are those of the authors and do not necessarily represent the official position of the Centers for Disease Control and Prevention.

\section{Publisher's Note}

Springer Nature remains neutral with regard to jurisdictional claims in published maps and institutional affiliations.

Received: 1 March 2017 Accepted: 26 April 2017

Published online: 03 May 2017
References

1. National malaria control programme. National malaria strategy 20162020. Angola: Ministry of Health; 2015

2. Cosep Consultoria, Consaúde, ICF International. Angola Malaria Indicator Survey 2011. Calverton, Maryland: Cosep Consultoria, Consaúde, and ICF International 2011.

3. Instituto Nacional de Estatistica. Angola: Standard DHS, 2015-16. 2016

4. Galactionova K, Tediosi F, de Savigny D, Smith T, Tanner M. Effective coverage and systems effectiveness for malaria case management in sub-Saharan African countries. PLoS ONE. 2015;10:e0127818.

5. Plucinski MM, Guilavogui T, Sidikiba S, Diakité N, Diakité S, Dioubaté M, et al. Effect of the Ebola-virus-disease epidemic on malaria case management in Guinea, 2014: a cross-sectional survey of health facilities. Lancet Infect Dis. 2015;15:1017-23.

6. Juma E, Zurovac D. Changes in health workers' malaria diagnosis and treatment practices in Kenya. Malar J. 2011;10:1.

7. Mavoko HM, Ilombe G, da Luz RI, Kutekemeni A, Lutumba P. Malaria policies versus practices, a reality check from Kinshasa, the capital of the Democratic Republic of Congo. BMC Public Health. 2015;15:352.

8. Rowe AK, Ponce de León GF, Mihigo J, Santelli ACF, Miller NP, Van-Dúnem P. Quality of malaria case management at outpatient health facilities in Angola. Malar J. 2009:8:275.

9. Roll Back Malaria Monitoring \& Evaluation Reference Group. Using facilitybased data for malaria programme monitoring and evaluation. Personal Communication 2015.

10. Lumley T. Analysis of complex survey samples. J Stat Softw. 2004;9(1):1-9.

11. Bennett A, Bisanzio D, Yukich JO, Mappin B, Fergus CA, Lynch M, et al. Population coverage of artemisinin-based combination treatment in children younger than 5 years with fever and Plasmodium falciparum infection in Africa, 2003-2015: a modelling study using data from national surveys. Lancet Global Health. 2017;5:e418-27.

12. Bilal JA, Gasim GI, Abdien MT, Elmardi KA, Malik EM, Adam I. Poor adherence to the malaria management protocol among health workers attending under-five year old febrile children at Omdurman Hospital, Sudan. Malar J. 2015;14:34.

13. Zurovac D, Githinji S, Memusi D, Kigen S, Machini B, Muturi A, et al. Major improvements in the quality of malaria case-management under the "test and treat" policy in Kenya. PLoS ONE. 2014;9:e92782.

14. Millar KR, McCutcheon J, Coakley EH, Brieger W, Ibrahim MA, Mohammed Z, et al. Patterns and predictors of malaria care-seeking, diagnostic testing, and artemisinin-based combination therapy for children under five with fever in Northern Nigeria: a cross-sectional study. Malar J. 2014;13:447.

15. Steinhardt LC, Chinkhumba J, Wolkon A, Luka M, Luhanga M, Sande J, et al. Quality of malaria case management in Malawi: results from a nationally representative health facility survey. PLoS ONE. 2014;9:e89050.

16. Johansson EW, Gething PW, Hildenwall H, Mappin B, Petzold M, Peterson SS, et al. Effect of diagnostic testing on medicines used by febrile children less than five years in 12 malaria-endemic African countries: a mixedmethods study. Malar J. 2015;14:194.

17. Rao VB, Schellenberg D, Ghani AC. The potential impact of improving appropriate treatment for fever on malaria and non-malarial febrile illness management in under-5s: a decision-tree modelling approach. PLoS ONE. 2013;8:e69654.

18. Tanahashi T. Health service coverage and its evaluation. Bull World Health Organ. 1978;56:295.

19. National malaria control programme. Routine malaria information system. Angola: Ministry of Health; 2016.

20. Ezzet F, Van Vugt M, Nosten F, Looareesuwan S, White N. Pharmacokinetics and pharmacodynamics of lumefantrine (benflumetol) in acute falciparum malaria. Antimicrob Agents Chemother. 2000;44:697-704.

21. Hrisos S, Eccles MP, Francis JJ, Dickinson HO, Kaner EF, Beyer FJ, et al. Are there valid proxy measures of clinical behaviour? A systematic review. Implement Sci. 2009;4:37.

22. Pulford J, Siba PM, Mueller I, Hetzel MW. The exit interview as a proxy measure of malaria case management practice: sensitivity and specificity relative to direct observation. BMC Health Serv Res. 2014;14:628. 